\title{
Food Connection for Golden Triangle, Taiwan
}

\author{
Chen Ting WU, Shenglin Elijah Chang \\ Graduate Institute of Building and Planning, \\ National Taiwan University, No.1,Section 4, Roosevelt Rd., 10617 Taipei, Taiwan ROC \\ jameswu182@hotmail.com
}

\begin{abstract}
This paper examines how exotic cuisines become the mechanism glue different ethnic groups together and enhanced the quality of community life in the so-called Golden Triangle in the Longgang area of Taoyuan, Taiwan. The Golden Triangle Longgang has been famous for its cultural diversities, especially the numbers of the exotic restaurants, including Burma cuisines, Hakka cuisines, Taiwanese cuisines, Chinese Mainlanders' cuisines, Islamic cuisines and so on. In this paper, the research particularly investigates the relationships between the Burma cuisines and the quality of community life within the Burma-Chinese ethnic groups.
\end{abstract}

Keywords: food;ethnic food;diaspora; Identity

eISSN: 2398-4279 @ 2017. The Authors. Published for AMER ABRA by e-International Publishing House, Ltd., UK. This is an open-access article under the CC BY-NC-ND license (http://creativecommons.org/licenses/by-ncnd/4.0/). Peer-review under responsibility of AMER (Association of Malaysian Environment-Behaviour Researchers), ABRA (Association of Behavioural Researchers on Asians) and cE-Bs (Centre for EnvironmentBehaviour Studies), Faculty of Architecture, Planning \& Surveying, Universiti Teknologi MARA, Malaysia.

https://doi.org/10.21834/ajqol.v2i8.66 


\subsection{Introduction}

In the era of globalization, scholars have identified that food cultures have been inevitably intertwining and blending with each other. David and Valentine (1997) explore cross-cultural consumptions of food from a variety of levels, from bodies, to families, to communities, to cities, to regions, to countries, and finally extending to the whole globe. They argue ethnic immigrants construct their personal identities and suppress their culturally bonded aesthetics through the preservations of their foods. Immigrants from various cultural origins often exchange with each other through blending with and learning from their cooking processes, seasoning preparations and combinations of cuisines. The blending of their tastes embodies the fusion of their identity.

Taiwan has long been a multi-ethnic society with immigrants carrying their food cultures. For most immigrants, they weight food cultures as important as their folk religions and homeland dialects. Indeed, eating is the everyday activities that sustain the inclusive ethnic networks for the exchange of goods, information, and place-based attachments (Wang and Shen, 2006). "Food is recognized as being expressive identity and integral component of cultural and heritage. Furthermore, foods are seen as a midpoint of culture identity, which belongs to specific society or ethnic, and some elements of food preparation and consumption are the visible badges of identity. "(Nor, et al. 2012) In other words, tastes of food lead to the links between ethnic foods and immigrant history, transformations of cultures, and the reshaping of places in Taiwan.

Following this line of thinking, the paper examines how particular immigrant food cultures transformed local places and community identities. The targeted "diaspora" (with a lower case "d") here refers to the communities that have dispersed across borders between China and Burma, the so-called golden triangle area, around the end of WWII. This group of immigrants In postmodern theory, concepts of edges, differences, flux, and resistance are used to counter the homogeneity and centrality of modernity. As Gilroy (1994) and Peters (1999) assert, diaspora is not just about attachment to and identification with nations and homelands, but also about shaping new identities, spaces, and commonalities in new contexts, as well as understanding intercultural connections and multiple identities against intersect backgrounds. Against the intertwined cultural complexities, food could act in strengthening the integrative force, solidarity and social bonding and alliances among the communities and ethnic groups. (Noriza,2013)

Based on qualitative research methods, the research team interviewed 80 individuals and 30 shops within twelve months. The team also applied observations and ethnographic methods. (Fig. 1).This paper focuses on the blending food cultures of Chinese civil war veteran groups, the Muslim groups and the local Taiwanese \& Hakkaness groups who migrated to the place several decades earlier. It investigates how the making of food indicates the interlacing of different groups, their migration experiences, and spatial interactions related to their old homes and the new ones from the golden triangle in Burma to Taoyuan, Taiwan. Taiwan's Taoyuan County is populated by various ethnic groups, 
including Hoklo, Hakka, indigenous Taiwanese, "mainlanders" (mainland Chinese arriving post the Chinese Civil War after 1947), and new immigrants; it is a microcosm of Taiwan's diverse society. The intermingling of these ethnic groups has created a diverse local culture. In particular, veteran communities are the product of Taiwan's unique history. Inhabited by retired soldiers from all over China, and most of them married with women form all over Taiwan, they form rich, diverse, and unique cultural communities in Taiwan society.

Among Taoyuan County, Zhongli City has the highest concentration of veteran communities. Within Zhongli, this paper examines veteran communities that are located in the area known as Longgang (means the dragon hill in Chinese), an important military location on the border between Zhongli and Pingzhen. Most of Longgang's veterans are soldiers who fled from border regions in Yunnan, Myanmar (or Burma as it was at the time), and Thailand. These veterans relocated in Longgang at different time periods. Their migration was overwhelmed with grief for being disconnected with their families and being uprooted from their motherland. They might not know each other before settling down in Longgang, however they shared similar war experiences and similar food cultures and customs.

Within Longgang, these veterans relocated from Yunnan and Burma mostly have been settling down in a veteran community named Zhongzhen New Villag. Compared to other veteran communities, Zhongzhen New Village was noted for its southwestern styles including Yunnan, Guizhou, Indochina, Thailand, Burma, Indonesia, Vietnam and so on. The Yunnanese and Burmese cuisine of Longgang is food for times of war. They were brought to Taiwan by troops stationed along the Yunnan-Burma border as mentioned before. Food from Indochina can also be found, making it a cuisine that blends the influence from diverse ethnicities and cultures. The most representative dish is Migan, a type of rice noodle.In Yunnanese cuisine, Migan is a white, semi-transparent noodle made by grinding fermented sticky rice into a paste, then steaming it and cutting the congealed rice paste into strips after it cools. In Yunnan, Migan is eaten as a sweet breakfast in peanut soup or soy milk. In Taiwan, however, it is served as a savory dish in bone stock, often with an egg and pork slices. (Fig. 2a).

With the addition of new immigrants and migrant workers in recent years, bringing in inhabitants from Southeast Asia, Longgang's food culture has only grown more diverse with elements from Islamic, Indonesian, and Vietnamese cuisine. The Longgang area has become the UN (united nation) for ethnic food (henceforth, the food UN) that visitors smelling and tasting ethnic flavors from all over. (Fig. 2b).

However, the food UN Zhongzhen New Village has been demolished in the name of progress since a decade ago. Veteran residents have been relocated to different parts of Taiwan. Luckily enough, these old-time veterans still feel a strong attachment toward the place. They have been creating numerous organizations and initiating cultural networks that bringing people back through everyday events, folk rituals, and cultural festivals. The 
"localized" diaspora experiences have also constructed an imagined home returning with delicious food landscapes for real.

- Based on qualitative research methods, the research team interviewed 80 individuals and 30 shops within twelve months.

- The team also applied observations and ethnographic methods.

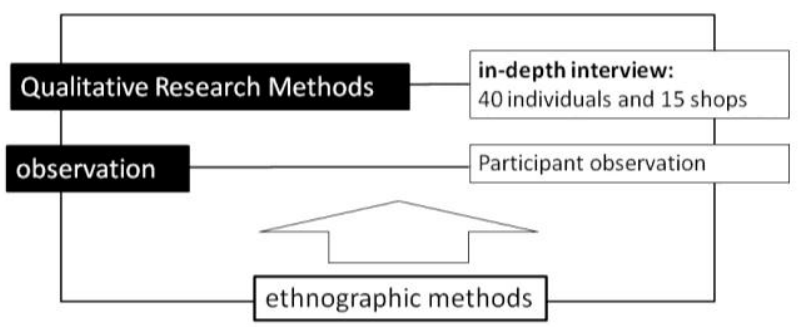

Figure 1: Research methods.

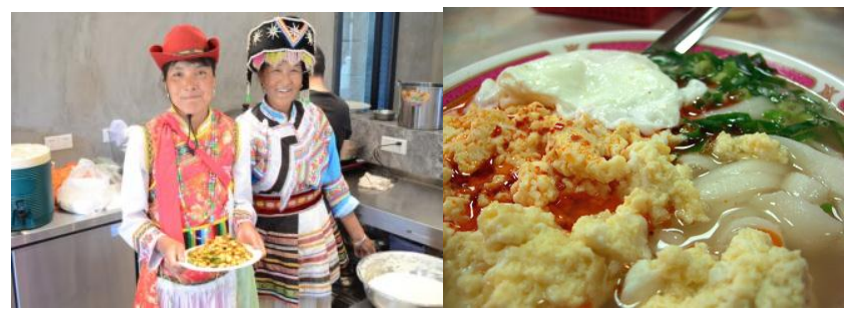

Figure 2: (a) Migan is a representative dish of Longgang ; (b)Traditional Yunnan minority clothing on display in a Yunnan-inspired shop.

\subsection{Migration}

The story begins in 1945, when China was once again plunged into civil war after negotiations between the Kuomintang (KMT) and the Chinese Communist Party fell apart. In 1949, the KMT was forced to retreat to Taiwan. Forces in Yunnan, then yet to fall into Communist control, moved south into the Golden Triangle area at the intersection of Burma, Thailand and Laos. These Yunnanese partisans were given the task of re-taking China. However, in the Golden Triangle, they became displaced soldiers in a strange land. After UN arbitration, these troops were later relocated to Taiwan. The story formed the basis of the novel "A Home Too Far", written by Bo Yang under the pseudonym Deng Kebao. The story was made into a film in the 1980s. These displaced troops were relocated to Taiwan in groups. They included Han Chinese and ethnic minorities from Yunnan, as well as Thai and 
Burmese minorities. In order to house these soldiers and their dependents, who totaled over 10,000 in number, the government chose the Longgang area located between the cities of Zhongli, Pingzhen, and Bade in Taoyuan County to build veteran communities. The Ministry of Defense also gave the troops the unit name of Zhongzhen, "loyalty and faith," reflecting the spirit with which they undertook the hard journey from Yunnan and Burma. Interviews show that these displaced troops on the Chinese border were left to fend for themselves as they wandered through the mountains of the Golden Triangle. A long period of migration was only concluded when a base for re-taking China was established on the border with Thailand and Burma. This experience of displacement and unrest in migration was embedded in the food and cultural habits these troops brought to Zhongzhen New Village. When they first arrived, these new migrants had difficulties adapting to life in Taiwan due to the unfamiliar language and environment. However, the bond of their shared experience in the Golden Triangle proved to be a tight connection that eventually gave rise to a cultural identity. (Fig. 3).

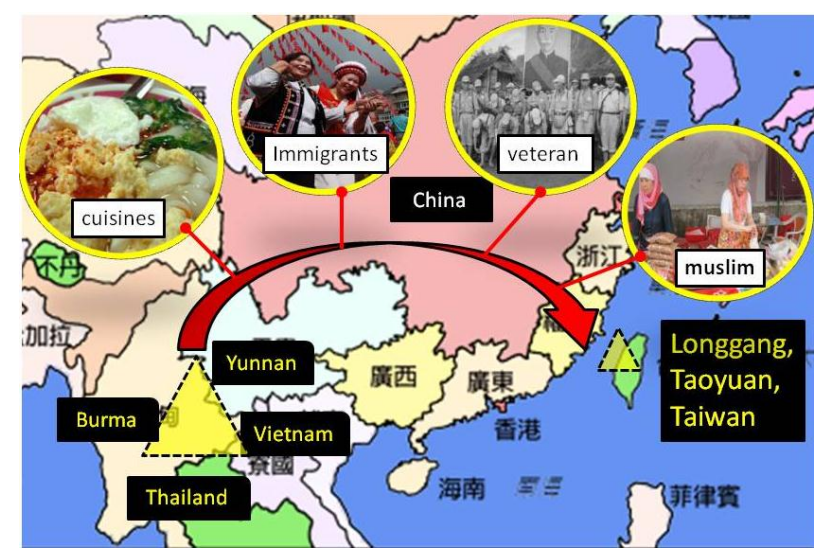

Figure 3: The History of migration in the golden triangle.

Major construction of veteran communities began in the 1950s. The Longgang area once had the highest concentration of such villages in Taiwan. The veteran communities were the most representative types of settlements for immigrants from China and became a center for the exchange of Chinese cuisines. In those economically difficult times, kitchens and ingredients were often shared in the dependents' villages. This gave rise to a cuisine that blended elements from different groups, comforted homesick veterans from all over China, and formed a collective memory for them all. The cuisine of Zhongzhen New Village was influenced by the conflict in the Golden Triangle, absorbing the habits and unique dishes of Yunnan and Burma. What had once been war food, a response to a difficult environment, gradually took root in Longgang. The area became a kitchen in which the food 
cultures of those displaced strangers came together and mingled. The concentration of military bases in these dependents' villages gave rise to the Zhongzhen Market in the streets and alleys around Zhongzhen New Village, fulfilling the needs of trade and daily life. In 1970, Zhongzhen Market had the highest concentration of Yunnanese food in Taiwan. Nearly every stall sold Migan. At its peak, there were over 50 Migan stalls in the market. In addition to snacks, local produce and crafts were also sold, as were exotic spices and foods rarely found in other markets. Afterwards, as workers from Southeast Asia arrived in Taiwan, and the number of foreign spouses increased, Thai, Vietnamese, and Indonesian foods were added to the mix. Longgang became the place to find exotic food in Taoyuan.

Therefore, Longgang is a core area for the development of diverse ethnic cuisines. Yunnanese and Burmese cuisine were the basis of the food culture landscape. Besides the relocated troops, many people from Yunnan also came to Taiwan through marriage or relatives. These newer immigrants also often made their living selling Migan. As foreign workers and spouses from Southeast Asia have grown in number in recent years, the Yunnanese-Burmese cuisine has also integrated elements from Thailand, Vietnam, and Indonesia. An ancient Chinese saying holds that trees bear different fruits in different soils. The Yunnanese and Burmese cuisines brought to Taiwan by relocated troops underwent innovation and intermingling with a never-ending stream of new immigrants, leading to new and unique flavors.

\subsection{Embedding}

The immigration pattern of the Longgang area is inseparable from globalized urban development patterns. As the city expanded, the veteran communities located in what was once the edge of the city became a source of land for urban development. Urban plans and veteran community reconstruction laws were rapidly passed. Many villages were demolished to make way for urban renewal projects. After the Act for Rebuilding Old Quarters for Military Dependents was passed in 1977, veteran communities all over Taiwan were gradually demolished to build public housing. The inhabitants were relocated to public housing projects in other areas. Most of Zhongzhen New Village was demolished in 1996; the inhabitants were scattered across the island. Luxury housing developments are currently being built on the old site of Zhongzhen New Village. For veterans and their dependents, this second period of displacement and relocation once again tore them away from their memories and an identity of place.

Some groups were forced to leave, but a group of immigrant Muslims eventually put down roots here. Most of the troops in the Golden Triangle were originally from Yunnan; many were Hui minority Muslims. Seeking a place to practice their faith in Taiwan, they built a mosque in Longgang in 1954, which became a center of faith for many people from Yunnan and Burma. Longgang's Muslim population was mostly born into a religion. They can be divided into three groups. The first is the Yunnanese soldiers and their descendants 
who lived in Zhongzhen New Village nearby. The second is descendants of Yunnan and Burma troops and overseas Chinese from Thailand and Burma, who were not born in Taiwan and mostly settled in Taiwan permanently after 1970. The third is the large number of Muslims who came to Taiwan from Southeast Asia temporarily for work or spouses of Taiwanese people from Southeast Asia. In Islam, there is a close relationship between the mosque and the community. The mosque is connected to every Muslim's faith, philosophy, education, lifestyle, and behavior. In the past 20 years, Longgang's mosque has become the core of community development and a symbol for the Islamic spirit. (Fig. 4a).

Taking food as an example, Muslims observe dietary restrictions and have strict requirements on how animals are killed and processed for food. Responding to the general lack of Muslim-oriented food options in Taiwan, halal-certified restaurants have emerged in Longgang. (Fig. 4b). The owners of these restaurants are not always Muslim themselves, but they provide food that is acceptable to Muslims, for whom these dishes and ingredients trigger nostalgia and memories of the familiar flavors of home. At the same time, the food has undergone localization, with ingredients, flavoring, and recipes adapted to local tastes. These dishes are not carbon copies of what Muslims would eat at home, but embedded in local relationships. Muslims come from different places, but they feel a sense of belonging through eating the same foods. The dining experience in Longgang's Muslim restaurants shapes a food landscape based on identity, resisting mainstream food trends. Food is a medium through which community connections are maintained.

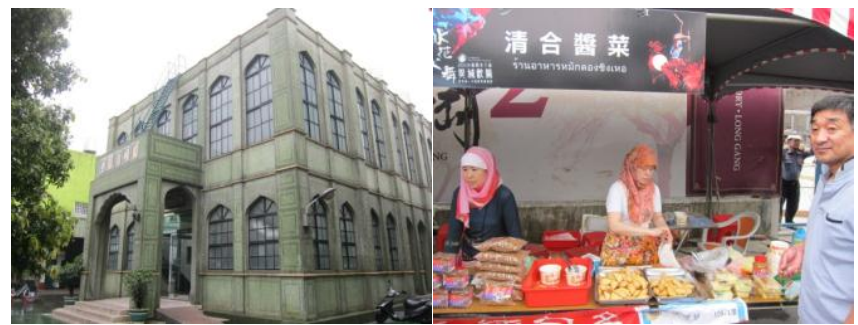

Figure 4: (a) Longgang's mosque ; (b) A Muslim restaurant sets up a stall in a festival to sell snacks and dried food.

\subsection{Integration}

Food is a way to shape identities and emphasize local characteristics. Zhongzhen New Village has been demolished, but the displaced troops from Yunnan and Burma still maintain a local emotional connection. They also started organizations like the Yunnan Border Friendship Organization and the Yunnan Association. When they were first relocated to Taiwan, this group of people mostly from Yunnan gradually formed a closed circle as they internalized their culture. After they were relocated from Zhongzhen New Village, the former inhabitants used the continued activities of the dance group, with their 
regular gatherings, to construct memories and imaginings of this strange land through a collective dance and music experience. The music also expressed and displayed the characteristics of their ethnic culture, rebuilding a diaspora identity based on the diaspora experience. In recent years, the government has stepped up efforts to collect oral histories of veteran communities and conduct other cultural and settlement surveys, in the name of a renaissance of veteran community culture. Cultural festivals such as the Military Housing Culture Festival have also been held. In 2011, the Longgang Migan Festival began, featuring traditional Yunnanese music, patriotic song performances and Yunnan folk activities. (Fig. 5ab). In 2014, the original celebration of food was expanded to include the Torch Festival celebrated by ethnic minority in Yunnan and the Songkran festival celebrated in Thailand. The two-week festival brought together the food, music, clothing, and activities of many cultures, and many people from outside visited. A more inclusive food landscape was constructed, gradually opening the closed cultural circle.

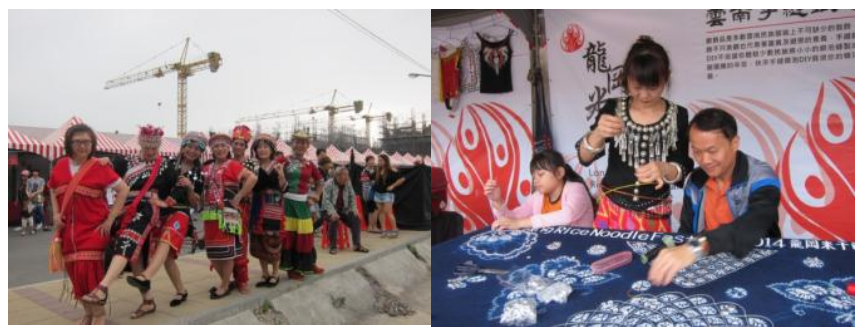

Figure 5: (a) The Migan Festival- featuring traditional Yunnanese music. ; (b) The Migan FestivalYunnan folk activities.

Huanga (2012) argues "Self-identification also comes from interpersonal interaction. People can realize self-value through educational activities and deem their community as the field that helped build their identification." Geographically, Longgang is located on the border between city and country. The traditional dichotomy where the urban and the rural are in conflict offers no insight into the real issues faced by diverse ethnic groups in the economic development of the area. Field studies show that the area's Golden Triangle (Bade, Zhongli, and Pingzhen) are now organically linked in terms of industry and daily lives. Zhongzhen New Village had no market in its earlier years, and inhabitants had to do their shopping in downtown Zhongli. The neighborhood chief of Zhongzhen Li struck a deal with farmers in Bade to sell their crops around the village, forming a small market that began exchanges between the villagers and Taiwanese locals. With the exchange of food, Zhongzhen Market grew larger and larger in scale into what it is today. The market became an important space for different ethnic groups to mingle. Today, cross-cultural cooperation through food continues. For example, the pork skin used in thin-sliced pork, a celebrated Yunnan dish, comes from pigs raised in Bade and Pingzhen. In addition, the Guinness World Record attempt in the 2014 Migan Festival used rice donated by Bade to make the 
Migan, a great example of a cross-cultural farm-to-table agriculture. The supply and demand of food production and consumption thus became the best example for promoting local economies, allowing industries and industrial activities of all groups to intermingle and expand, opening new possibilities in cross-cultural industries.

\subsection{Conclusion}

Where is home? For people forced to leave their homes due to politics or an armed upheaval in Taiwan and the world, this is a complicated question. For the displaced veterans of Longgang, their migration from the Golden Triangle of Southeast Asian to the Golden Triangle of Taiwan was not just a geographical migration; it carried deeper and more complex meaning. Based on their shared experience and similar food cultures and habits, these people developed a way to integrate through their connections to that distant place. In Longgang, where diverse ethnic groups intermingled, they adapted to the new living space and provided themselves with a sense of stability. Nowadays, the number of new immigrants is growing. The varying diaspora experiences of these groups have become the source of unique cuisines. The cuisines have become a source of identity for many ethnic groups today while religious faith has become a force for cuisine to blend ethnic elements. This paper takes the perspective of food in reflecting on the attitudes taken by traditional planners regarding urban and rural areas. In the face of shortcomings in planning and theory, this paper seeks new meaning in cross-cultural food research. It is hoped that the paper will contribute to the search for identity and integration in locations in the Asia-Pacific region such as Longgang.

\section{References}

Clifford, J. (1994). Diaspora. Cultural Anthropology, 9(3), 302-338.

Chih-Hung Wang , \& Meng-Ying Shen .(2009). Territorialization, Interstitial Interface and Transnational Space:The Taipei "Vietnam Street" as an Ethnic Place. Taiwan: A Radical Quarterly in Social Studies, 73, 102-113.

D. and Valentine, G.(1997). Consuming geographies : we are where we eat. London: Routledge.

Hui Chin Huanga, Zong Jun Lib, Cha-Shane Lia \&\& Shenglin Elijah Changa.(2012).Installing Young Dreams into the Old Town in Taiwan: Townscape Education as a Catalyst for the Cross-Cultural Youth to Develop the Historical Dasi Together, Procedia - Social and Behavioral Sciences, 50, 102-113.

Noriza Ishak, Mohd Salehuddin Mohd. Zahari , \& Zulhan Othman.(2013).Influence of Acculturation on Foodways among Ethnic Groups and Common Acceptable Food. Procedia - Social and Behavioral Sciences, 105, 438-444.

Norazmir Md. Nor, Mohd Shazali Md. Sharif , Mohd Salehuddin Mohd Zahari , Hannita Mohd Salleh, Noriza Isha, \& Rosmaliza Muhammad.(2012). The Transmission Modes of Malay Traditional Food Knowledge within Generations.Procedia - Social and Behavioral Sciences, 50, 79-88. 
Wu, C.T. \& Chang, S.E. / Asian Journal of Quality of Life, AjQoL, 2(8) Oct / Dec 2017 (p.13-22)

Peters, J. D. (1999). Exile, Nomadism, and Diaspora: The Stakes of Mobility in the Western Canon. in Naficy, H. (ed.), Home, Exile, Homeland (pp. 17-41). New York and London: Routledge.

Vloreen Nity Mathew, Ardiana Mazwa Raudah binti Amir Abdullah, \& Siti Nurazizah binti Mohamad Ismail . (2013).Acceptance on Halal Food among Non-Muslim Consumers. Procedia - Social and Behavioral Sciences, 121, 